\title{
Influencia de un aditivo no comercial sobre la calidad de los yesos en construcción
}

\section{GALVAÑ LlOPIS, M. SORIANO CUBELLS, L. PALAIA PEREZ, A. MAS TOMAS y V. MONZO HURTADO}

Cátedra de Materiales de Construcción, Departamento de Construcciones Arquitectónicas, E.T.S. Arquitectura, Universidad Politécnica de Valencia, Camino de Vera, $\mathbf{s} / \mathbf{n}$

\section{RESUMEN}

En el presente trabajo se ha estudiado la influencia sobre la calidad de un determinado tipo de yeso, al incorporar como "aditivo" $0,96 \%$ de cloruro de potasio (KCl), comprobando la variación on el comportamiento mecánico, asi como en los tiempos de principio y final de fraguado. También mediante el uso de la Microscopla Electrónica de Barrido (M.E.B.), se han observado los resultados obtenidos al emplear el citado aditivo y se han comparado con los valores encontrados para las probetas patrón.

\section{SUMMARY}

At the present paper, it shows how thas been studied the influence over the quality of a special sort of gypsum, when it has been added as "additive" 0,96\% of potasium chlorurus (KCl), it has been observed the variation on the mechanical proprieties and also over the time of the beginninng and end of the set. Also with the use ot a scanner Electronic Microscopic (M.E.B.), it has been observed the results obtained using such additive and it has been made a comparison with the finded values for the standard specimen.

\section{INTRODUCCION}

Las aplicaciones diversas del yeso necesitan toda una amplia gama de productos especiales que permitan obtener velocidades de fraguado bien definidas, manteniéndose constantes y acotadas entre ciertos limites. Es decir, cada aplicación del yeso requerirá, además de un comportamiento mecánico adecuado, la obtención de tiempos para pasar del estado líquido al plástico y la duración del estado plástico, que permitan la mejor trabajabilidad del material y su fácil aplicación.

En la bibliografía se recogen algunos aditivos utilizados para modificar las velocidades de fraguado. No obstante, las investigaciones $\|$ evadas a cabo en esta Cátedra de Materiales de Construcción se centran en estudiar los efectos de ciertas sustancias, tradicionalmente utilizadas como aditivos por los "guixaires", para la puesta en obra del yeso. En concreto, se ha determinado la cantidad de yeso correspondiente al amasado de saturación, el tiempo de duración del estado plástico y el tiempo en pasar del estado líquido al plástico (valores extrapolados a partir de las especificaciones de la norma UNE 102-010-83), y las resistencias a flexotracción y compresión de un yeso de construcción, adicionado "subrepticiamente" con $\mathrm{KCl}$.

Además, la utilización de la MEB ha permitido comparar resultados y justificar los diferentes comportamientos.

\section{EXPERIMENTACION Y RESULTADOS}

La parte experimental se llevó a cabo en el laboratorio de Construcción de la Escuela Técnica Superior de Arquitectura de Valencia.

El procedimiento seguido para la determinación de las características físicas y mecánicas se especifica en la norma UNE 102-031-82, según se recoge en el actual Pliego General de Condiciones para la recepción de yesos y escayolas en las obras de construcción (RY-85).

El aditivo utilizado fue cloruro potásico $(\mathrm{KCl})$, $y$ el tipo de yeso empleado el denominado Y-12, según el Pliego del año 1972, equivalente al yeso tipificado como $Y G$ según el vigente Pliego RY-85. 
La preparación de las probetas normalizadas se realizó manteniendo constante la relación agua/yeso e igual a $0,8(600 \mathrm{~cm}$ de agua y $750 \mathrm{~g}$ de yeso). El aditivo se incorporó al agua de amasado en un porcentaje igual al $1,2 \%$ en peso, equivalente a 7,2 g. La pasta resultante se introdujo en el molde metálico para la obtención de tres probetas de $4 \times 4$ $x 16 \mathrm{~cm}$. De esta forma, se realizaron seis amasadas con agua y yeso únicamente (patrón) $y$ otras seis incorporando el aditivo.

Por cada amasada se prepararon tres probetas y se ensayaron seis probetas de cada tipo a flexotracción (patrón y con aditivo), y doce a compresión. Las probetas restantes quedaron como testigos o para la realización de otros tipos de ensayos.

Para la determinación de los tiempos de fraguado y resistencias mecánicas a flexotracción y compresión se siguió lo explicitado en los apartados 5,6 y 7 de la mencionada norma UNE 102-031-82.

En la tabla I se muestran los resultados encontrados para la resistencia a flexotracción y compresión, mientras que en la tabla II se indican los valores correspondientes a los tiempos de fraguado.

De los valores que se muestran en la tabla I, se deduce que la incorporación del aditivo no supone apenas variación en los valores medios de resistencia a flexotracción y compresión, si bien se observa que los coeficientes de variación obtenidos son mayores cuando se ensayan las probetas fabricadas con adición de $\mathrm{KCl}$ al yeso. Este hecho se debe a la distribución no uniforme del aditivo durante el amasado de las pasta.

En cuanto a los tiempos de fraguado (Tabla II) se aprecia que la incorporación de $\mathrm{KCl}$ provoca

TABLA I

Resistencias mecánicas

\begin{tabular}{|c|c|c|c|c|c|c|}
\hline & \multicolumn{3}{|c|}{ Flexotracción } & \multicolumn{3}{|c|}{ Compresión } \\
\hline & $\begin{array}{c}- \\
X \\
(\mathrm{~kg} / \mathrm{cm})\end{array}$ & $\begin{array}{c}S D \\
(n=6)\end{array}$ & $\begin{array}{l}\text { CV } \\
(\%)\end{array}$ & $\begin{array}{c}- \\
X \\
(\mathrm{~kg} / \mathrm{cm})\end{array}$ & $\begin{array}{c}S D \\
(n=12)\end{array}$ & $\begin{array}{l}\text { CV } \\
(\%)\end{array}$ \\
\hline PATRON & 11,2 & 0,7 & 6,25 & 26,9 & 0,3 & 1,1 \\
\hline $\mathrm{KCl}$ & 10,0 & 1,0 & 10,00 & 27,0 & 4,0 & 14,8 \\
\hline
\end{tabular}

54
TABLA II

Trabajabilidad

\begin{tabular}{|l|c|c|}
\hline & $\begin{array}{c}\text { Princlplo de fraguado } \\
\text { (minutos) }\end{array}$ & $\begin{array}{c}\text { Final de fraguado } \\
\text { (minutos) }\end{array}$ \\
\hline $\begin{array}{l}\text { PATRON } \\
\mathrm{KCl}\end{array}$ & $\begin{array}{c}10^{\prime} 00^{\prime \prime} \\
5^{\prime} 00^{\prime \prime}\end{array}$ & $\begin{array}{c}1^{\prime} 30^{\prime \prime} \\
6^{\prime} 00^{\prime \prime}\end{array}$ \\
\hline
\end{tabular}

una sensible disminución de los mismos con respecto a los valores encontrados para las probetas patrón.

Se realizó también un estudio comparativo mediante la utilización de la M.E.B., de las probetas patrón y de las probetas con aditivo, con el fin de explicar la gran dispersión de los resultados encontrados en cuanto a la trabajabilidad. Para ello, las muestras a ensayar fueron debidamente preparadas, desecándolas a peso constante en estufa a $65^{\circ} \mathrm{C}$, y posteriormente fueron metalizadas con oro.

Durante la realización de este ensayo se tomaron las fotografias que se adjuntan, y que permiten justificar los diferentes comportamientos, obteniendo imágenes a 50x, 500x y 1.500x aproximadamente.

En particular, las imágenes a $500 x$, permiten observar que la adición de $\mathrm{KCl}$ confiere mayor densidad a la muestra, mientras que las imágenes a $1.500 x$ muestran la presencia de otros cristales diferentes a los de sulfato de calcio que, actuando como "centro de cristalización", inducen a la precipitación de los cristales de yeso, justificándose así las diferencias entre los valores encontrados.

\section{CONCLUSIONES}

La introducción de estos iones extraños en esta disolución aumenta la solubilidad de la sal presente en la misma, como consecuencia de un aumento de la fuerza iónica, y disminución de la actividad de los iones inicialmente presentes. Así, pues, la adición de $\mathrm{KCl}$ al yeso en las proporciones indicadas provoca un aumento de la solubilidad del sulfato de calcio, al disminuir la actividad de los iones calcio y sulfato. En particular, este efecto será más sensible sobre el semihidrato que sobre el dihidrato por ser el primero más soluble que el segundo.

El aumento de la solubilidad del sulfato de calcio semihidrato permite su posterior hidratación y una mayor aceleración del fraguado, 


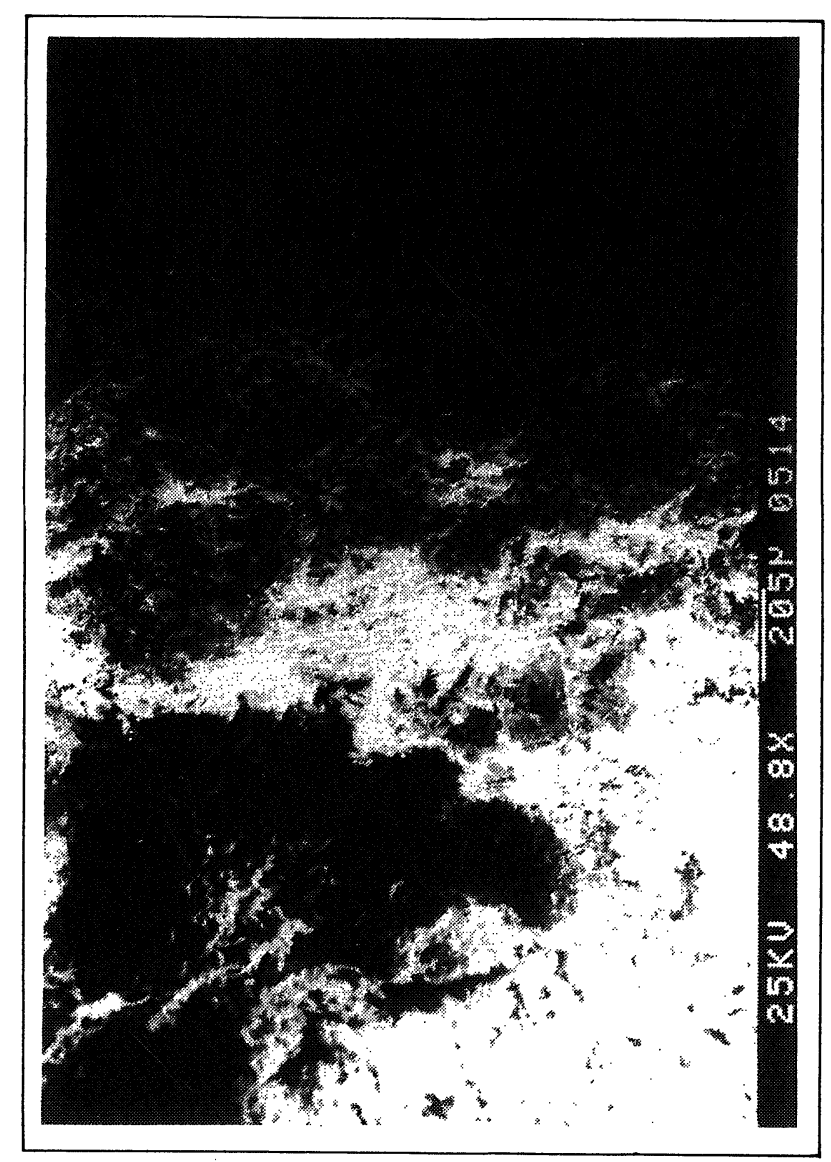

Muestra Patrón

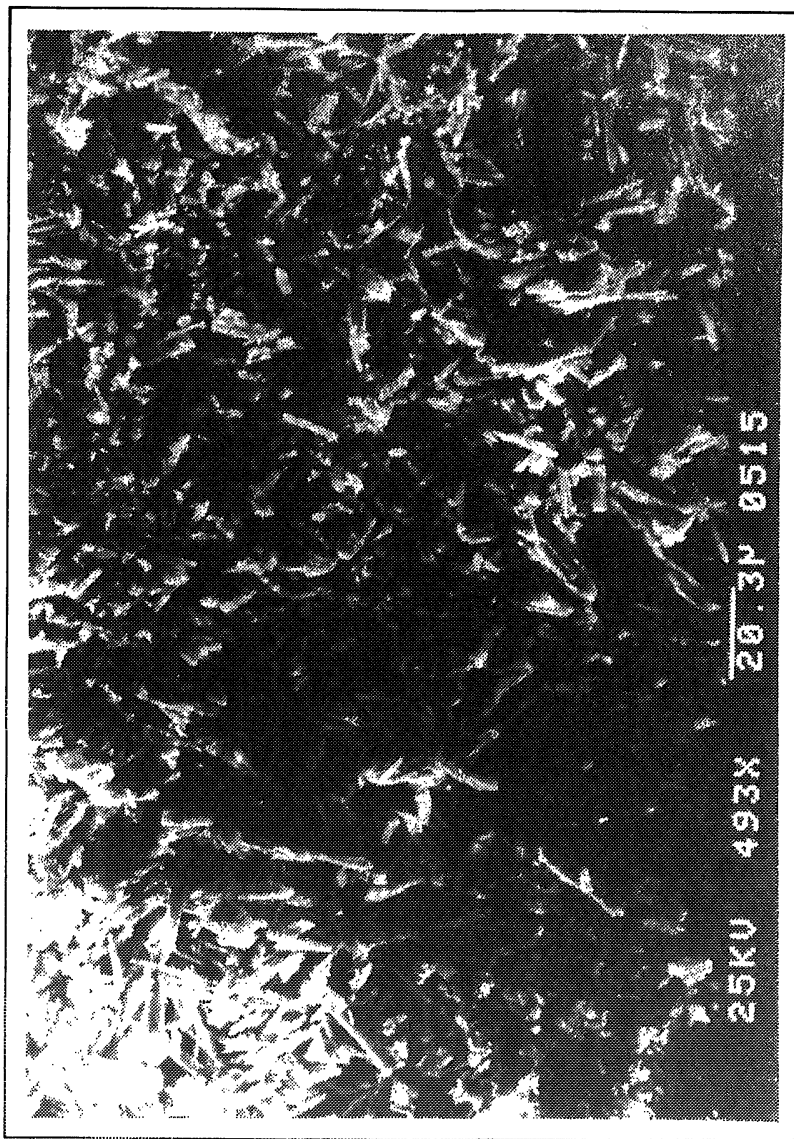

$493 x$

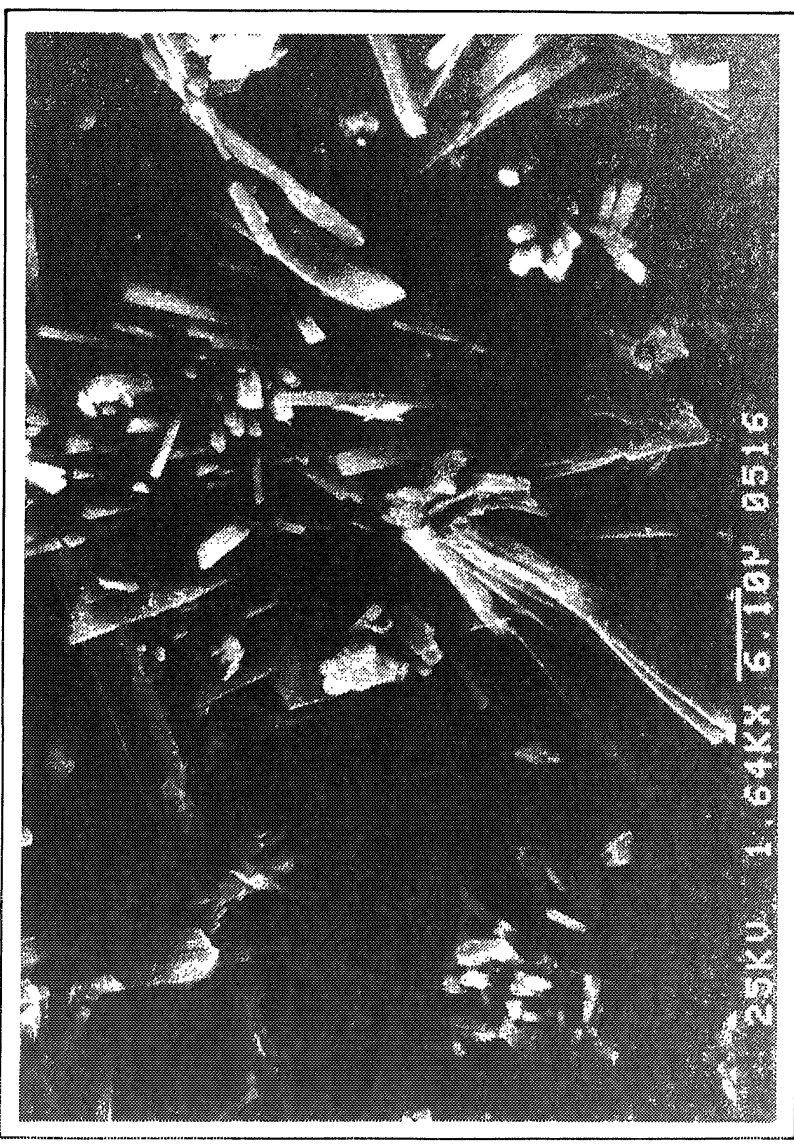

$1.640 x$ 


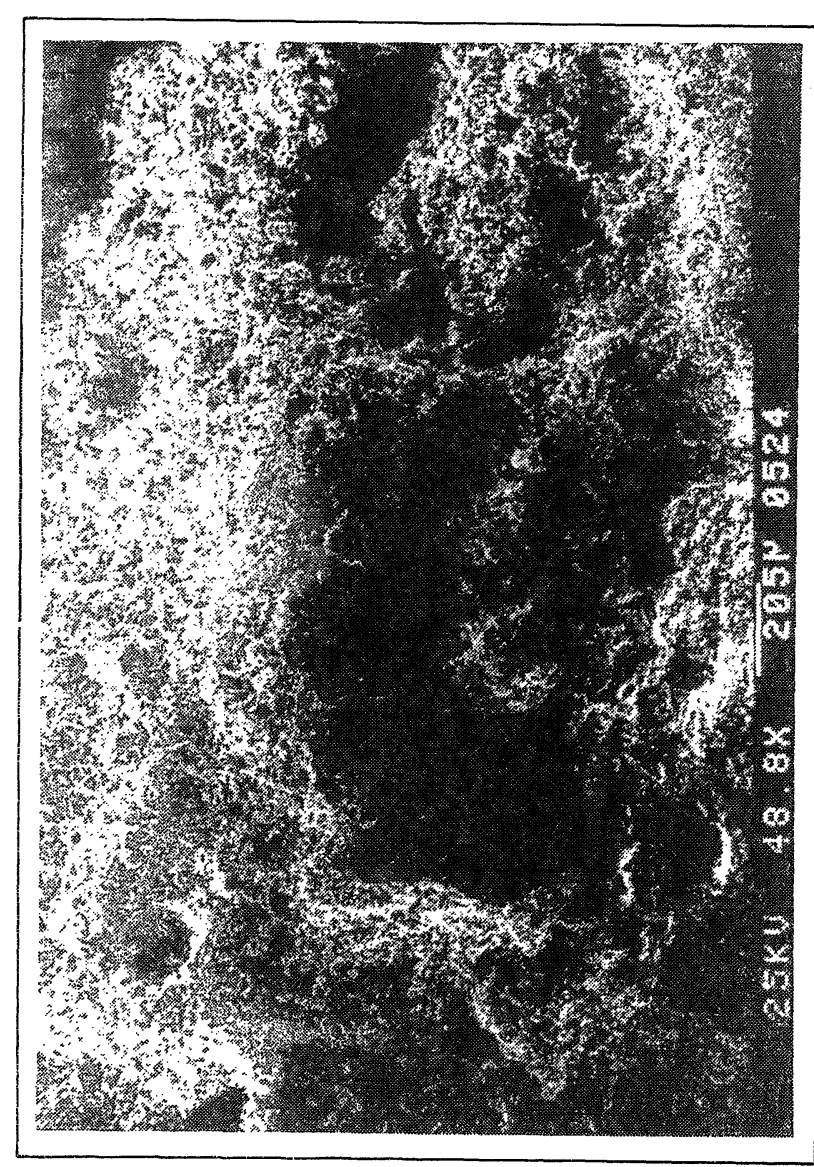

Muestra de CIK

$48 x$

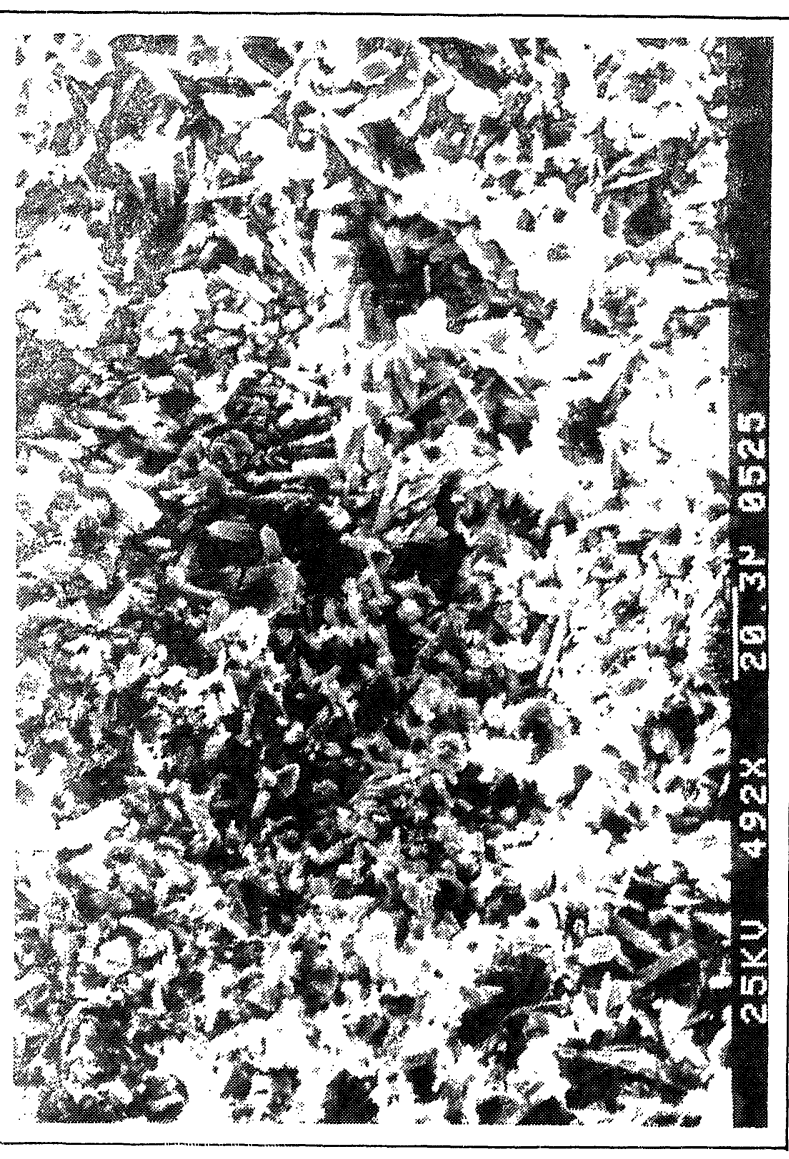

$492 x$

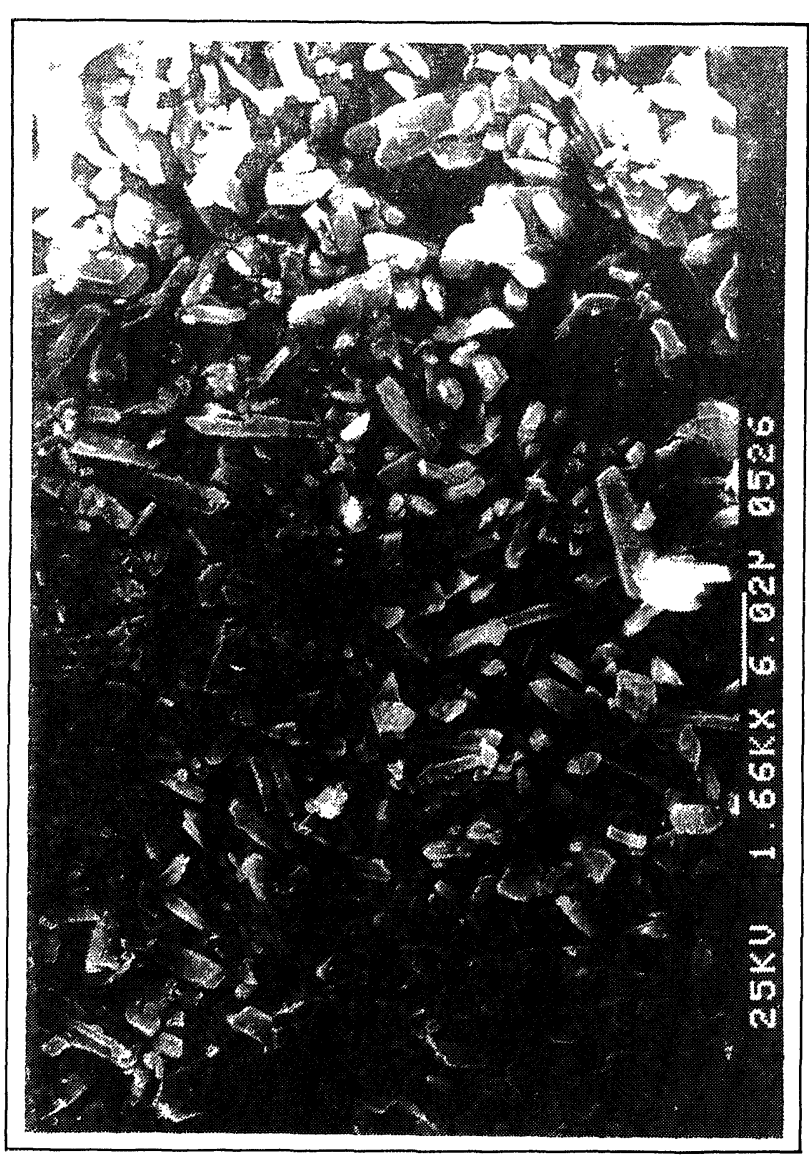

$1.660 \mathrm{x}$ 
lo que equivale comparativamente a un descenso de su trabajabilidad; es decir, la adición de este aditivo "subrepticio", en la cantidad estudiada, ocasiona contrariamente a lo que cabria esperar un menor tiempo de puesta en obra, sin modificar sus características mecánicas. Consecuentemente, su utilización debería de ser para elementos que necesitaran una gran rapidez de "endurecimiento", o lo que es lo mismo, solamente sería útil para elementos de apeo provisional y/o para elementos prefabricados manteniendo las constantes mecánicas de estabilidad.

\section{COROLARIO}

Sin lugar a dudas, se podría aseverar, que las condiciones "normales" de utilización de los yesos en construcción, no requieren esta rapidez de puesta en obra, si no todo lo contrario (mayor trabajabilidad). Esta idea implica necesariamente un conocimiento de la calidad y cantidad de los materiales a utilizar 0 , lo que es lo mismo, olvidar las "recetas" y entender que las modificaciones no estudiadas pueden, y normalmente así es, causar deterioros (yeso muerto) en las construcciones.

\section{BIBLIOGRAFIA}

* MURAT M.: "La Microscopia Electronique a Balayage". La Chimica en L'Industria. SPA Editrice di Chimica, Milano 1985.

* DIAMOND S.: "Application of Scanning Electron Microscopy to the study of hidrated cement". Proceding of The Annual Scanning Simposium. Chicago 1970.

* FOUCAULT M.: "Controle des enduits du plâtre". Revue des materiaux de construction, 667, 1985.

* DALIGANT D.: "Le plâtre et ses techniques du production". Ciments, Betons, Plâtres, Chaux, 753, 1985.

" MURAT M.: "Correlations texture cristaline-proprietes mecaniques des plâtres durcis". Materiaux et constructions, $8,47,1985$.

* LUCAS G.: "Métodos de medida del fraguado de los yesos retardados". Comite Científico-Técnico de la Eurogypsum.

* MOISSEY J. M.: "Modificateurs de Prise des Plâtres". Ciments, Betons, Plâtres, Chaux, 765, 1985.

* NEGRO-STAFEERIL: "Aplication du microscope electronique a balayage". Revue des materiaux de construction, $684,1985$.

\section{publicación del ICCET/CSIC}

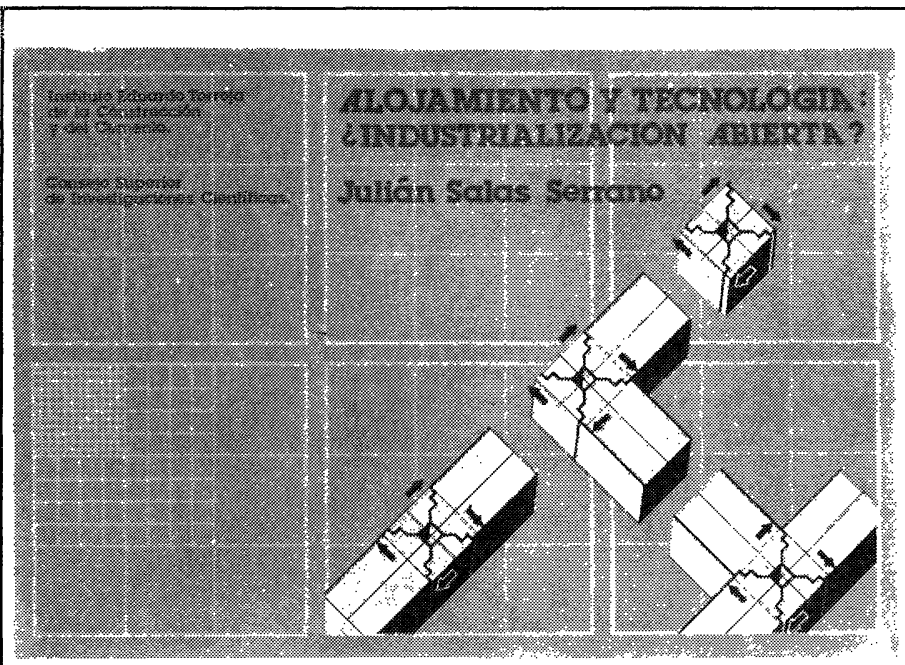

ALOJAMIENTO Y TECNOLOGIA: ¿INDUSTRIALIZACION ABIERTA?

JULIAN SALAS, ING. IND. (I.E.T.C.C.) Un volumen de 160 páginas, 109 figuras y 16 tablas. Tamaño $240 \times 168 \mathrm{~mm}$. Encuadernado en rústica. Precios: España, 1.200 ptas; extranjero, 17 \$ USA.

\section{SUMARIO:}

Prólogo Prof. G. Ciribini.

\section{Introducción}

Capítulo 1.- La industrialización en las proclamas y manifiestos de arquitectura.

Capitulo 2.-¿Réquiem por la construcción industrializada?

Capitulo 3. - Algunos conceptos básicos.

Capítulo 4. - ¿Proyecto tradicional, construcción industrializada?

Capitulo 5.-Componentes.

Capitulo 6. - La coordinación dimensional hoy.

Capítulo 7.-Flexibilidad, intercambiabilidad y catálogos.

Capitulo 8. - Industrialización, normativa y calidad.

Capitulo 9.- Reflexiones finales.

publicación del

INSTITUTO EDUARDO TORROJA 